Open Access

\title{
The impact of Chinese political efficacy and political participation on their trust in the police
}

Rong $\mathrm{Hu}$

Correspondence:

hurong@xmu.edu.cn

Department of Sociology and Social

Work, Xiamen University, Xiamen,

China

\begin{abstract}
In English literature, the study of the public's evaluation of the police has been increasing in the past 10 years. Although the existing literature has talked about the influence of political participation on the trust of the police, it has not been studied from the perspective of political efficacy and political participation of the police. Based on the data of the Chinese General Social Survey (CGSS) 2010, this paper studies the influence of the Chinese people's political efficacy and political participation on the police trust. General ordered logic model shows the following: (1) external efficacy increases police trust greatly while internal efficacy reduce police trust; (2) although public resistance reduces police trust, participation in grassroots election increases police trust to certain extent.
\end{abstract}

Keywords: Police trust, Political participation, Internal efficiency, External efficiency

\section{量 Springer}

\section{Background}

Beginning in 1980, reform in China has brought great progress in many social and economic sectors; however, the social gap between the rich and the poor has further expanded, social conflicts intensified, and mass incidents frequently happened (Wu \& Sun 2009). Especially during the process of rapid urbanization in recent years, as a large number of farmers lost their land due to land acquisition, farmers' protests take place in the country with both the number and size of those protests continuously growing (Bernstein and Lu 2003; Tanner 2004). Police is a crucial power of maintaining social order as well as the order of the Commission. While stability was considered as the first social priority (Wang 2004), the police is often at the front line of maintaining stability, confronting with protestors. Police is an important state machine in public administration; therefore, people's trust towards the police composes a key part of political trust. In such context, the study of police trust and its influencing factors bears much theoretical and practical significance.

In the existing Chinese literature, no empirical researches were found on police trust. However, in the past few years, there are a growing number of literatures regarding public opinion towards the police in China (Cao and Hou 2001; Lai et al. 2010; Wu and Ivan 2009; 2010; Sun et al. 2012, 2013a, b). Despite that existing researches relate the influence of political participation on the trust of police, studies on police trust have not been

(c) 2016 Hu. Open Access This article is distributed under the terms of the Creative Commons Attribution 4.0 International License (http://creativecommons.org/licenses/by/4.0/), which permits unrestricted use, distribution, and reproduction in any medium, provided you give appropriate credit to the original author(s) and the source, provide a link to the Creative Commons license, and indicate if changes were made. 
touched upon from the perspective of political participation and political efficacy. The theory of political efficacy not only plays an important role in the study of political behavior and political socialization (Easton and Dennis 1967; Hess and Torney 1967; Hahn 1998) but also in the study of public trust in the police. In fact, if citizens have higher political efficacy, they would have confidence (internal efficiency) in knowledge and ability to influence government decision-making, at the same time, in government to respond to their demands (external efficiency), meaning possibly higher trust to the police and government. Thus, studying police trust from the perspective of political participation could include more aspects ignored in existing research before (Sun et al. 2012), in particular, the impact of grassroots election on police trust. Based on this, this paper will explore the internal and external efficiencies and the influence of various forms of political participation on police trust.

Based on the 2010 Chinese general social survey data, this research will explore political efficiency (internal efficiency and external efficiency) and the impact of three forms of political participation (rightful resistance, social participation, and grassroots election) on police trust. Next, we will establish hypothesis on the basis of combing political efficacy, political participation, and relative literature, followed by analyzing influence of political efficacy and political participation on police trust via linear regression and generalized logistic regression analysis. Finally, all findings are analyzed and discussed.

\section{Literature review and research hypothesis Political efficiency}

Political efficacy refers to the faith citizens have on their influence in the government, is a kind of feeling "feeling that political and social change is possible and that the individual citizen can play a part in bringing about this change" (et al. 1954, p. 187). In the study of political efficacy, political scholars usually divided it into two kinds of efficacy: internal efficiency and external efficacy. Internal efficacy refers to an individual's belief on his or her knowledge and ability to influence the system (Sullivan and Riedel 2001). Such efficacy often shows the possibility of individual participating in voting or becoming political activists. The external efficacy refers to individual believing in the possibility and the extent of the government's response to his or her demands. External efficiency relates to the extent of government concerned about the needs of individuals. Low external efficacy often performs as political apathy, meaning citizens could not recognize the government as representative of their opinions. Political efficacy may predict participation of election voting but also reflecting publics' attitude towards government and the degree of acceptance of anti system movement (Sullivan and Riedel 2001). Voters with low political efficacy tend to support pro-reform candidates, although they are not necessarily going to vote, because they do not believe their actions are of significance in the political process. Individual with higher political efficacy are more likely to vote, because they believe in their influence on the government, and they tend to support the incumbent, because they think the government is able to represent them well (Sullivan and Riedel 2001). The current research indicates political efficacy will be influenced by various factors, such as political participation (Finkel 1985, 1987), political education degree (Pasek et al. 2008), 
the degree of contact with media (Kenski and Stroud 2006), race, health, age, gender, the degree of education and social and economic status (Schur et al. 2003; Michelson 2000; Huo 2005; Kahne and Westheimer 2002), and political socialization of young people (Easton and Dennis 1967; Hess and Torney 1967; Hahn 1998).

Since 1950, many researchers have studied the relations of political efficacy, trust, and political behavior. In fact, political efficacy is closely related to trust. If sense of efficacy refers to a belief in one's own ability, then trust indicates a faith in others (including system). Trust could be divided into political trust and interpersonal trust. Political trust can be seen as "a basic evaluation of the response of the government to the people's normal expectations" (Hetherington 1998, p. 791). Therefore, from a broad perspective, the object of political trust includes government agencies and political systems. On the other hand, interpersonal trust or social trust means "an expectation held by an individual or a group that the word, promise, verbal or written statement of another individual or group can be relied upon" (Rotter 1967, p. 615). Trust normally could be distinguished as particularized trust and generalized trust, the former indicates trust to close friends, relatives, and family members, and the latter one refers to the trust to less closed friends, or society in general (Newton and Zmerli 2011; Uslaner 2002). In past researches, trust is often regarded as an important social capital, and particularized trust is regarded as bonding capital while generalized trust is regarded as bridging capital (Brehm and Rahn 1997; Putnam 1993, Putnam 2000). Studies show that although political trust and interpersonal trust are related and interact mutually, the two could be differentiated in concept (Putnam 2000; Schyns and Koop 2013; Uslaner 2002). Some researcher studied relations between political efficacy and political trust (Aberbach and Walker 1970, p. 1204). When political efficacy is low, people do not trust the government and they believe that their actions can hardly affect political leaders' action. By contrast, when political efficacy is high, people believe that the government's actions are considerate for the people, and people's actions will have a positive impact on the government. Relatively high political efficacy is imperative to democratic stability because in the modern democratic society, citizens should feel that they have the ability to influence the government (Wright 1975, p. 69). Further researches illustrate that external efficacy could directly improve political trust, while the influence of internal efficacy on political trust remains quite weak and unclear (Aberbach and Walker 1970; Balch 1974; Catterberg \& Moreno 2006;Cole1973; Niemi et al. 1991).

Police trust is a part of political trust; however, so far few researches have examined the impact of political efficacy on police trust. One exception is Wu and Ivan's (2009) analysis of public trust in the police, which included a scale of perceived political knowledge, power, and influence that somewhat tapped into both internal and external political efficacies. They discovered that people who are equipped with relatively high political efficacy tend to have comparatively high degree of trust in police. Our research will continue discussing this issue under China's social background. In this research, we will discuss the influence of internal efficacy and external efficacy on police trust. Based on the review of above literature, we could set up hypotheses as below:

Hypothesis 1: external efficacy could increase police trust, and people with higher external efficacy will have higher police trust. 
Hypothesis 2: internal efficacy may reduce police trust, and people with higher internal efficacy will demonstrate lower police trust.

\section{The political participation of Chinese urban and rural residents}

Many scholars who have studied politics in communist countries do not recognize any political participations of conceptual significance in this society. Scholars using totalitarian model emphasize the elite's overall control of the society, and the monopoly control of the mass media in these societies successfully limits the circulation of information. By restricting the freedom of association, the government can effectively prevent union of the people by interest, so that the people lose their ability to resist political authority (Friedrich et al. 1969, p. 126). Although the interest group theory acknowledges that the government does not completely eliminate the boundaries between the state and society nor completely stop expressions of interest, the model still denied the possibility of ordinary people to influence policy decisions. In such societies, political activities and organizations (such as election, mass movement, the unions and peasant associations, and so on) are controlled by the authorities, aiming to eliminate voluntary group formation. Thus, these activities and organizations do not provide the function of interest expression.

On the other hand, this does not indicate that the public can not affect the decision of the government. With some scholars extending the definition of political participation in a broader concept, the original unidimensional view of political participation (those who regard vote as the only way and the key to affect political process) is replaced by a multidimensional one. For example, some scholars have defined the political participation as legitimate activities carried out by the common people and aimed at influence the choice of the government personnel or their acts more or less (Nie and Verba 1975). Some scholars' studies in the Soviet and other former communist countries in Eastern Europe indicate that the people of these countries also expressed their interests in their own way and had an impact on the government's decision. If elections are more likely to become a mere formality as a political ritual, then the public in these countries will choose alternative means other than elections, such as personal contact, to seek the help of government officials or to express their own preference. For instance, Inkles and Bauer's research shows "Soviet citizens seem much less concerned with winning political rights and constitutional guarantees than with gaining more personal security and an improved standard of living" (Inkles and Bauer 1959, p. 7). Bialer's research indicates that Soviet citizens more frequently participated in the decisions related to their daily life, community affairs, and working conditions (Bialer 1980, p. 166). These researches find that people's political participation demonstrates its own uniqueness in those societies, for example, people are more likely to make attempt to influence policy implementation rather than the decision process, and their participation are more often carried out in a personal, informal, and atomistic approach (see Jennings 1997).

With regard to China, high level government officials are not elected directly by people, and citizens are unable to articulate their interests through a public and open electoral process. Although key officials at all levels of government are elected indirectly by representatives of people' congresses, candidates are nominated by the 
Communist Party and not by the general citizenry at large. Therefore, a public electoral process is not an important concern regarding political participation under this system. However, since the 1980s implementation of a village autonomy, village committee members are now elected directly by villagers every 3 years. Village elections are competitive elections and to a great extent have gradually become an important way for villagers to articulate their interests and hold committee members responsible for village policies (Hu 2001, 2005). Although a big gap remains between competitive elections in rural areas and neighborhood community elections in urban areas, urban neighborhood community committee to a certain degree is elected by the community residents. For both urban and rural residents, their participation in the activities of the village committee or neighborhood committees can largely increase their chances of contacting with police, especially with those who work in the local police stations. Through participating in grassroots elections and community affairs, urban and rural residents can enhance their communication with and knowledge of police. Therefore, we suggest the following:

Hypothesis 3: the higher degree of participation in grassroots election, the greater police trust will people have.

If participation in grassroots election and community affairs is a form of institutionalized political participation, the struggle for rights of urban and rural residents is a form of non-institutionalized political participation. In the past decades, struggles for civil rights occurred in different places and different forms. O'Brien employed the concept of "rightful resistance" to describe such struggles in rural areas of China (O'Brien 1996). When farmers face with corruption, environmental pollution, indiscriminate charges, land acquisition, and otherissues, they would fight to protect their interests. Rightful resistance is a form of partially institutionalized mass protest that the aggrieved people attempt to legitimize their own demands by working within state laws, policies, and political rhetoric (O'Brien 1996). Rightful resistance is different from other forms of mass protest which directly challenges the legitimacy of the regime. Those strugglers accept the legitimacy of the law, policy, and the core value of the national law, and they fight only when they believe that the government officials failed their commitment or violated the law or social values (O'Brien 1996; O'Brien and Li 2006). With China's reform and the growing awareness of civil rights among Chinese citizens, the Chinese public began to use administrative (Shangfang/petition) and legal channels to solve their problems and make the local authorities responsible for them.

In spite of current scholarly attention to political participation of Chinese people, especially the petition and protest, the relationship between political participation and police trust has not yet been studied. As a variety of people's political activities will affect their perceptions of the police, it is reasonable to believe that there is a linkage between political participation and police trust. Since the actions of the protestors are often opponent to the police who work in the front line of maintaining social stability, we set up the following: 
Hypothesis 4: the more participant in struggle with the law, the lower trust they will have towards the police.

\section{Methods}

\section{Data and variable measurement}

All data comes from the 2010 Chinese General Social Survey (CGSS). CGSS is a national, comprehensive, continuous, large-scale social survey project established by Renmin University of China, beginning from 2003, changed from for the first 2 years to now once a year. In 2010, the CGSS was designed by using the multi-order stratified probability sampling design, and the survey points were all over Mainland China. Samples are drawn from 100 counties (area) plus five big cities, Beijing, Shanghai, Tianjin, Guangzhou, and Shenzhen, as the primary sampling unit. Four neighborhood committees or village committees from each selected county (area) were randomly selected. It also planned to investigate 25 families from every neighborhood committees and village committees with one randomly selected person to be investigated from each family. From Beijing, Shanghai, Tianjing, Guangzhou, and Shenzhen, researcher selected 80 neighborhood committees, planning to investigate 25 families in every committee and inquiring into one person from each family randomly. Therefore, the total investigated samples amounts to 12,000 people. When extracting the primary sample unit (country and area) and secondary sample unit (village committees and neighborhood committees ), researcher utilized demographic data for paperwork; while when extracting families from village committees and neighborhood committees, researcher employed map method to draw field sampling; when inquiring into individual, researcher used KISH table to extract field sampling.

\section{Dependent variable}

The dependent variable in the research is the police trust of the respondents, questions include: to what extent do you trust the police? Answers contain the following: "not trust at all," "somewhat not trust," "between not trust and trust," "somewhat trust," and "completely trust" (Table 1).

\section{Predictive variable}

The core predictive variables are divided into political efficacy and political participation. Political efficacy measurement contains two index, external efficacy factor and internal efficacy factor. The factor analysis of the following five items was obtained by means of the questionnaire: (1) I believe I have ability to participate in politics; (2) I

Table 1 Respondents' police trust

\begin{tabular}{lll}
\hline Choice & Frequency & Percentage \\
\hline "Not trust at all" & 311 & 2.66 \\
"Somewhat not trust" & 861 & 7.35 \\
"Between not trust and trust" & 1892 & 16.15 \\
"Somewhat trust" & 4832 & 41.18 \\
"Completely trust" & 3825 & 32.66 \\
Total & 11,712 & 100.00 \\
\hline
\end{tabular}


could be totally qualified for government cadres if I had chance; (3) my suggestions to the government will be accepted; (4) government cadres will pay attention to our attitude and view towards government; and (5) I know how to make leaders know my advice or comments for government departments. The answers are divided into the following: (1) strongly disagree, (2) disagree, (3) indifferent, (4) agree, and (5) strongly agree. The Cronbach's alpha coefficient from the five items is 0.674 , which indicates relative high intrinsic consistency. We use the principle component factor method to analyze; two factors were extracted by maximum variance method, named as "external efficacy factor and internal efficacy factor." External efficacy factor includes the third, fourth, and fifth items (factor loadings are 0.81, 0.80, and 0.72; eigenvalue is 1.84; explained variance is $36.89 \%$ ); internal efficacy factor consists of the first and second items (factor loadings are 0.90 and 0.91 ; eigenvalue is 1.70; explained variance is $34.01 \%$ ).

We use the following three variables to measure political participation. First, asking respondents whether or not have they participated in seven activities as below: (1) work for village committee, neighborhood committee, or owners' committee; (2) offering suggestion or opinion to village committee, neighborhood committee, or owners' committee; (3) joining group petition; (4) writing a joint letter; (5) reporting a problem of residential areas to media; (6) reporting a problem of residential areas to relevant government departments; and (7) joining protest or petition. Answers are "participated" (1) and "not participated" (0). The Cronbach's alpha coefficient in these seven projects is 0.922 , which shows there is a high degree of consistency between these items. We used the principal component method to carry out factor analysis, and the maximum variance method was used to extract two factors, named as "protest by law factor" and "community involvement factor." Protest by law factor comprises the third, fourth, fifth, and seventh items (loadings are 0.76, 0.72, 0.42, and 0.71; eigenvalue is 1.99; explained variance is $28.36 \%$ ); community involvement factor concludes the first, second, sixth projects (load factors are 0.79, 0.81, and 0.47; characteristic value is 1.58; explained variance is $22.63 \%$ ).

The third variable that measures political participation is grassroots election participation; a question was provided as below: "Did you vote in the last village committee or neighborhood committee election?" Answers are "voted" (1) and "not voted" (0).

\section{Controlled variable}

The controlled variables of this study include some demographic information and social trust. Age is an interval level of measure. Education level is an ordinal measurement, i.e., below primary school $=1$, secondary school $=2$, high school $=3$, diploma $=4$, and bachelor and above $=5$. Gender $($ male $=1)$, registered residence (rural household registration "1," urban household registration "0"), party member (party member $=1$ ), Han nationality ( $\operatorname{Han}=1$, non-Han nationality $=0$ ), and religious affiliation (have religious affiliation $=1$, do not have religious affiliation $=0$ ) are dummy variables. Class mobility is the difference between respondents who recognized their own class identity at present and that of 10 years ago: "in our society, some groups are at the top level, while some others at the bottom level, the following is a top-down table. 10 represents the top, and 1 represents the 
bottom." We ask respondents what kind of level they were 10 years ago and what about now, and then use rank in now minus 10 years ago as the variable of class mobility. Social justice is measured by asking respondents whether they think contemporary society is justice or not in general. Answers are divided as "completely injustice," "relatively injustice," "neutral," "relatively justice," and "completely justice," scoring from " 1 " to " 5 ."

Social trust contains two factors: general trust and particularized trust, deriving from factor analysis of eight measurements of social trust. We request respondents to answer their levels of trust to eight kinds of different objects: family members, relatives, friends, colleagues, leaders, businessman, classmates, and hometown villagers. Answers are "not trust at all," "somewhat not trust," "between not trust and trust," "somewhat trust," and "completely trust," scoring from "1" to "5." The Cronbach's alpha coefficient of these eight items is 0.808 , indicating that those items have relatively high degree of reliability. We used principle component method to analyze these eight items via maximum variance rotation, and to extract factors of general trust and particularized trust. Factor of general trust includes trust on friends, colleagues, leaders, businessman, classmates, hometown villagers (factor loadings are $0.57,0.72,0.71,0.69,0.68$, and 0.72 ; eigenvalue is 2.915; explained variance is $36.44 \%$ ). Particularized trust factor contains trust to family members and relatives (factor loadings are 0.81 and 0.75 ; eigenvalue is 1.731; explained variance is $21.63 \%$ ).

Table 2 demonstrates descriptive statistics for all variables. In order to eliminate the collinearity among the variables, we detected the correlation coefficient among all the independent variables, and the results indicate that there is a certain degree

Table 2 Descriptive statistics of variables in regression analysis

\begin{tabular}{llllll}
\hline Variables & Mean & SD & Min & Max & Number \\
\hline $\begin{array}{l}\text { Dependent variables } \\
\text { Police trust }\end{array}$ & 3.94 & 1.01 & 1 & 5 & 11,712 \\
$\begin{array}{l}\text { Independent variables } \\
\text { External efficacy }\end{array}$ & 0 & 1 & -2.31 & 2.89 & 11,403 \\
Internal efficacy & 0 & 1 & -1.91 & 2.61 & 11,403 \\
Rightful resistance & 0 & 1 & -0.74 & 15.17 & 11,662 \\
Community participation & 0 & 1 & -3.10 & 5.91 & 11,662 \\
Grassroots election participation & 0.48 & 0.50 & 0 & 1 & 11,166 \\
Controlled variables & & & & & \\
Gender & 0.48 & 0.50 & 0 & 1 & 11,783 \\
Age & 47.31 & 15.69 & 17 & 96 & 11,779 \\
Education & 2.22 & 1.23 & 1 & 5 & 11,777 \\
Registered residency & 0.51 & 0.50 & 0 & 1 & 11,781 \\
Religious or not & 0.13 & 0.34 & 0 & 1 & 11,752 \\
Han nationality or not & 0.91 & 0.29 & 0 & 1 & 11,761 \\
Class mobility & 0.68 & 1.64 & -9 & 9 & 11,716 \\
Social justice & 2.99 & 1.09 & 1 & 5 & 11,754 \\
Universal trust & 0 & 1 & -4.05 & 4.20 & 10,952 \\
Special trust & 0 & 1 & -8.10 & 2.08 & 10,952 \\
\hline
\end{tabular}


of negative correlation between the registered permanent residence and education $(-0.501)$ which is acceptable.

\section{Results}

The dependent variable of this study, police trust, is an ordinal variable. At present, ordinal variables are usually treated as nominal variables or as interval variables. The former reduces measurements to nominal variables which will lose some information, while the latter is not rigorous enough. A more popular method is to set up ordinal logistic regression, but the premise is that parallel test is not significant which our study's data could not satisfy. Therefore, in our research, we mainly conduct generalized ordinal logistic regression (general ordered logit model) in analysis, and at the same time, we use linear regression model as supplement. The model of generalized ordinal logistic regression (Gologit) could show as follows:

$$
P(Y i>j)=g\left(X \beta_{j}\right)=\frac{\exp \left(\alpha_{j}+X_{i} \beta_{j}\right)}{1+\left[\exp \left(\alpha_{j}+X_{i} \beta_{j}\right)\right]} \quad, j=1,2, \ldots \quad, M-1 .
$$

The $M$ is the total sequence number of the ordinal variable. In this research, $M=5$, when $j=1$, comparing the first and the second, third, fourth, fifth; when $j=2$, the first and second compared with the third, fourth, and fifth; when $j=3$, the first, second, and third compares with the fourth and fifth; when $j=4$, the first, second, third, and fourth compared with the fifth.

Let us start with the result of ordinary least squares (OLS) regression model when police trust is regarded as a dependent variable. The model shows that, besides gender and religious affiliation, all other controlled variables and the dependent variable are statistic significant correlated. Specifically, with the growing of age, police trust increases, whereas increasing the level of education reduces police trust. Rural residents have higher level of police trust than those urban residents. Han nationality respondents have lower police trust than that of ethnic minority respondents. Moreover, both general trust and particularized trust could enhance public's police trust, while upward social mobility and sense of justice could enhance police trust to a large degree. As the main predictive variables of this study, the influence of external efficacy and internal efficacy variables show opposite influence on police trust, the former increases police trust to a large extent, while the latter reduces police trust. This result is consistent with our hypothesis. Among the three indicators of political participation, community participation has no statistical significant relationship with the dependent variable, while rightful resistance and grassroots election have. The former reduces trust to police, while the latter one increases police trust. The interaction term of Hukou (registered residence) and grassroots election participation reveal that participation of urban community election creates higher police trust than participation of rural village committee election does (Table 3).

Let us take a look at the results of Gologit model now. As previously mentioned, using linear regression model or ordinal logistic regression is not rigorous to deal with the problem of ordinal variables. Through establishing generalized ordinal logistic regression, we can precisely predict the impact of a unit of independent variable on dependent variable as well as on which specific answer and to what extent. In order to 
Table 3 Factors affecting police trust: OLS regression model

\begin{tabular}{|c|c|c|c|}
\hline & Regression coefficient & Standard error & Significance \\
\hline \multicolumn{4}{|l|}{ Controlled variables } \\
\hline Gender & -0.029 & 0.018 & 0.104 \\
\hline Age & 0.003 & 0.001 & 0.000 \\
\hline Education & -0.050 & 0.009 & 0.000 \\
\hline Registered residency & 0.168 & 0.029 & 0.000 \\
\hline Religious or not & 0.047 & 0.028 & 0.029 \\
\hline Han nationality or not & -0.129 & 0.033 & 0.000 \\
\hline Class mobility & 0.207 & 0.009 & 0.000 \\
\hline Social justice & 0.105 & 0.009 & 0.000 \\
\hline Universal trust & 0.016 & 0.006 & 0.004 \\
\hline Special trust & 0.176 & 0.009 & 0.000 \\
\hline \multicolumn{4}{|l|}{ Predictive variables } \\
\hline \multicolumn{4}{|l|}{ Political efficacy } \\
\hline External efficacy & 0.146 & 0.009 & 0.000 \\
\hline Internal efficacy & -0.084 & 0.010 & 0.000 \\
\hline \multicolumn{4}{|l|}{ Political participation } \\
\hline Rightful resistance & -0.031 & 0.009 & 0.001 \\
\hline Community participation & -0.017 & 0.009 & 0.063 \\
\hline Grassroots election participation & 0.125 & 0.027 & 0.000 \\
\hline Hukou $\times$ grassroots election participation & -0.108 & 0.037 & 0.003 \\
\hline Constant & 3.321 & 0.065 & 0.000 \\
\hline N & 9985 & & \\
\hline Adjust $R^{2}$ & 0.2087 & & \\
\hline
\end{tabular}

Notes: odd ratio has been listed in the table

${ }^{*} p<0.05 ;{ }^{* *} p<0.01 ;{ }^{* * *} p<0.001$

$1=$ not trust at all

2 =somewhat not trust

3 =between not trust and trust

$4=$ somewhat trust

5 =completely trust

be more intuitive to monitor the impact of independent variables on dependent variable, we show the odds ratio in the table. In line with the linear regression model, the control variable gender is not statistically significant correlated to dependent variable. In terms of the impact of age on the police trust, there is no significant difference between the first group ("not trust at all vs. others") and the second group ("not trust at all + somewhat not trust vs. others"), except in comparison between the fourth group and the third group, as the age increasing, police trust increases (odds ratio greater than 1). Similar situation reveals the impact of the level of education on dependent variables, although in an opposite direction (odds ratio smaller than 1). That is to say, in comparison to the first group ("not trust at all and others") and the second group ("not trust at all + somewhat not trust vs. others"), the influence of education level is not significant, except in comparison between the third and the fourth group, the improvement of education level significantly reduces police trust. Rural respondents have higher level of police trust in total than urban respondents. However, in the comparison between the first group and the second group, there is no significantly difference, only in comparison between the third group and the fourth, rural residents 
have significant higher level of police trust than urban residents. In other words, in comparison with the third group, the possibility of rural residents choosing "somewhat not trust" and "trust a lot" is 42.8 \% higher than urban residents, in contrast to the possibility of the first three choices ("don't really trust at all," "somewhat not trust," and "in the middle"). Religious affiliation has a certain degree of effect on dependent variable. On the whole, religious respondents have higher degree of police trust than non-religious ones, but the influential level and the significance of the different groups are different.

The odds ratio of the influence of Han nationality over non-Han on dependent variable is less than 1 . Hence, Han nationality on the whole has lower police trust than ethnic minority, but only the third and the fourth group demonstrates statistically significant results. General trust could improve respondents' police trust to a large extent, while particularized trust also could improve respondents' police trust, although the latter had less influence than the former. Upward social mobility has weak influence on police trust, while the sense of social justice could improve respondents' police trust to a large extent (Table 4).

By taking a further step to analyze the impact of independent variables on dependent variable via generalized logistic regression model, we have findings as below. First, external efficacy could significantly improve police trust. The external efficacy affects dependent variable significantly, and the odds ratio of every group is larger than 1 , illustrating that the higher external efficacy respondents have, the greater police trust they possess. In particular, in the first group, if the external efficacy increases 1 unit, the possibility of respondents choosing "somewhat not trust + between not trust and trust + somewhat trust + completely trust" will increase $50.6 \%$ than choosing "not trust at all"; in the second group, if the external efficacy increases 1 unit, the possibility of choosing "between not trust and trust + somewhat trust + completely trust" will improve $51.2 \%$ in contrast with choosing "not trust at all + somewhat not trust"; in the third group, the external efficacy increases 1 unit, the possibility of choosing "somewhat trust + completely trust" raises $40.7 \%$ than choosing "not trust at all + somewhat not trust + between not trust and trust"; in the fourth group, the external efficacy raises 1 unit, the possibility of choosing "completely trust" increases $35.1 \%$ in comparison with choosing "not trust at all + somewhat not trust + between not trust and trust + somewhat trust." Therefore, hypothesis 1 can be verified.

Secondly, internal efficacy could reduce respondents' police trust significantly. The influence of internal efficacy on dependent variable is statistically significant, and each group in the table shows odds ratio less than 1, meaning that influence of the internal efficacy on police trust is negative, namely, the greater internal efficacy of respondents have, the lower degree of police trust. Specifically, in the first group, if internal efficacy increases 1 unit, the possibility of respondents choosing "somewhat not trust + between not trust and trust + somewhat trust + really a lot" reduces $23.6 \%$ (equals $0.761-1$, the same as below) in contrast with choosing "not trust at all"; in the second group, if the internal efficacy increases 1 unit, the possibility of choosing "between not trust and trust + somewhat trust + completely trust" will decrease $14.7 \%$ than choosing "not trust at all + somewhat not trust"; in the third group, with internal efficacy increasing 1 unit, the possibility of choosing "somewhat trust + completely trust" drops $12.7 \%$ in comparison with choosing "not trust at all + somewhat not trust + between not trust 
Table 4 Factors affecting police trust: generalized ordinal logistic regression (Gologit)

\begin{tabular}{|c|c|c|c|c|}
\hline & $\begin{array}{l}\text { First group } \\
1 \text { vs } 2-5\end{array}$ & $\begin{array}{l}\text { Second group } \\
1-2 \text { vs } 3-5\end{array}$ & $\begin{array}{l}\text { Third group } \\
1-3 \text { vs } 4-5\end{array}$ & $\begin{array}{l}\text { Fourth group } \\
1-4 \text { vs } 5\end{array}$ \\
\hline \multicolumn{5}{|l|}{ Controlled variables } \\
\hline Gender $($ male $=1)$ & 0.834 & 0.910 & 0.918 & 1.021 \\
\hline Age & 1.001 & 1.004 & 1.005 & 1.011 \\
\hline Education & 0.978 & 0.953 & 0.893 & 0.826 \\
\hline Registered residence (village $=1$ ) & 1.207 & 1.219 & 1.428 & 1.459 \\
\hline Religious or not (religious $=1$ ) & 1.611 & 1.079 & 1.252 & 0.911 \\
\hline Han nationality or not $(\operatorname{Han}=1)$ & 0.651 & 0.809 & 0.686 & 0.732 \\
\hline Universal trust & 1.912 & 1.848 & 1.779 & 1.399 \\
\hline Special trust & 0.993 & 1.120 & 1.269 & 1.525 \\
\hline Class mobility & 1.036 & 1.033 & 1.054 & 1.014 \\
\hline Social justice & 2.099 & 1.599 & 1.452 & 1.357 \\
\hline \multicolumn{5}{|l|}{ Predictive variables } \\
\hline \multicolumn{5}{|l|}{ Political efficacy } \\
\hline External efficacy & 1.506 & 1.512 & 1.407 & 1.351 \\
\hline Internal efficacy & 0.764 & 0.853 & 0.873 & 0.828 \\
\hline \multicolumn{5}{|l|}{ Political participation } \\
\hline Rightful resistance & 0.926 & 0.932 & 0.948 & 0.996 \\
\hline Community participation & 0.896 & 0.915 & 0.991 & 0.996 \\
\hline Grassroots election participation & 1.431 & 1.233 & 1.290 & 1.272 \\
\hline Hukou $\times$ grassroots election participation & 0.910 & 0.895 & 0.801 & 0.796 \\
\hline N & 9985 & & & \\
\hline Log-likelihood & $-11,735.937$ & & & \\
\hline Pseudo $R^{2}$ & 0.1062 & & & \\
\hline
\end{tabular}

Notes: odd ratio has been listed in the table

${ }^{*} p<0.05 ;{ }^{* *} p<0.01 ;{ }^{* * *} p<0.001$

$1=$ not trust at all

2 =somewhat not trust

$3=$ between not trust and trust

$4=$ somewhat trust

$5=$ completely trust

and trust"; in the fourth group, the internal efficacy increases 1 unit, the possibility of choosing "completely trust" lessens $17.2 \%$ in comparison with choosing "not trust at all + don't somewhat trust + between not trust and trust + somewhat trust." Therefore, hypothesis 2 can be verified.

Thirdly, rightful resistance reduces respondents' police trust to some extent. In particular, in the first group, if rightful resistance increases 1 unit, the possibility of respondents choosing "somewhat not trust + between not trust and trust + somewhat trust + completely trust" reduces $7.4 \%$ comparing to choosing "not trust at all"; in the second group, rightful resistance increases 1 unit, the possibility of choosing "between not trust and trust + somewhat trust + really trust" will decrease 6.8 \% comparing to choosing "not trust at all + somewhat not trust"; in the third group, rightful resistance increases 1 unit, the possibility of choosing "somewhat trust + completely trust" decreases $5.2 \%$ comparing to choosing "not trust at all + somewhat not trust + between not trust and trust"; in the fourth group, rightful resistance increases 1 unit, the possibility of choosing "completely trust" lessens $4 \%$ comparing to choosing "not trust 
at all + somewhat not trust + between not trust and trust + somewhat trust." Thus, hypothesis 4 can be verified.

Fourth, community participation decreases police trust to some extent. To be specific, in the first group, if community participation increases 1 unit, the possibility of respondents choosing "somewhat not trust + between not trust and trust + somewhat trust + completely trust" reduces $10.4 \%$ comparing to choosing "not trust at all"; in the second group, community participation increases 1 unit, the possibility of choosing "between not trust and trust + somewhat trust + completely trust" will decrease 8.5 \% comparing to "not trust at all + somewhat not trust"; in the third group, community participation increases 1 unit, the possibility of choosing "somewhat trust + completely trust" decreases $9 \%$ comparing to choosing "not trust at all + somewhat not trust + between not trust and trust"; in the fourth group, community participation increases 1 unit, the possibility of choosing "completely trust" lessens $4 \%$ comparing to choosing "not trust at all + somewhat not trust + between not trust and trust + somewhat trust." Odds ratio in the first two groups is statistically significant, while the latter two groups show no statistical significance. In spite of this, the influence of community participation on dependent variable is relatively clear, namely, the more frequent community participation respondents have, the lower level of police trust. The results are inconsistent with the hypothesis.

Fifth, participation in grassroots election could increase respondents' police trust in some ways. The influence of grassroots election on police trust in the four groups' odds ratios are larger than 1 , and all data show statistical significance, which means that grassroots election have positive impact on police trust. In particular, in the first group, if grassroots election increase 1 unit, the possibility of respondents choosing "somewhat not trust + between not trust and trust + somewhat trust + completely trust" increases 43.1 \% comparing to choosing "not trust at all"; in the second group, grassroots election increases 1 unit, the possibility of choosing "between not trust and trust + somewhat trust + completely trust" will raises $23.3 \%$ comparing to choosing "not trust at all + somewhat not trust"; in the third group, grassroots election increases 1 unit, the possibility of choosing "somewhat trust + completely trust" increases $29 \%$ comparing to choosing "not trust at all + somewhat not trust + between not trust and trust"; in the fourth group, grassroots election increases 1 unit, the possibility of choosing "completely trust" adds $27.2 \%$ comparing to choosing "not trust at all + somewhat not trust + between not trust and trust + somewhat trust." The Hukou-grassroots election interaction term ("Hukou $\times$ grassroots election") only shows weak statistical significance in relation to dependent variables in the last two groups. The odds ratios in the four groups are less than 1, thus we could assume that the influence of the interaction term on dependent variable is negative. It further illustrates that grassroots election's impact on police trust differs from urban to rural areas. The influence on urban residents is significantly larger than on rural residents.

\section{Discussion}

Based CGSS data in 2010, this paper examines the impact of political efficacy and political participation on police trust in Chinese urban and rural residents by controlling demographic variables of the respondents and social trust. We assume that the 
higher level of political efficacy as well as higher degree of participation in community affairs and grassroots elections at the grassroots level can enhance police trust, while participation in rightful resistance could weaken the level of police trust. Our research indicates that political efficacy and political participation have significant relations to police trust. In spite of some minor differences, our discovery is highly consistent with existing studies on other countries.

First, we find that external efficacy could enhance urban and rural residents' police trust. If respondents feel confident on their influence on government to response to their petition, they usually hold positive opinion towards police. Current studies abroad found that external efficacy has a positive correlation to government trust (such as Catterberg \& Moreno 2006; Niemi et al. 1991), which is consistent with our findings. Our research also echoed with scholarly studies on China rural area that external efficacy could enhance positive attitude of rural residents towards incumbent leader and the village's autonomous administration (Chen 2007). Although China is a "high power distance society" (Hofstede 2001), the finding of external efficacy's positive influence on political trust is also suitable for urban and rural residents in China.

Our finding further reveals that internal efficacy and political participation are influential to urban and rural residents' police trust. Take the uncertain correlation between internal efficacy and political trust in past literature in consideration (such as Morrell 2003), it was not surprise to discover a negative correlation between internal efficacy and police trust. Albeit the government's response to the public's demands can improve the latter's trust in the political system, the respondents who have higher confidence to their own ability would expect more on government agencies. Therefore, it is more likely to evoke anti-establishment emotions and to cause lower police trust. Future research should explore more on the negative relationship between internal efficacy and political trust.

Moreover, we find that two kinds of political participation, rightful resistance and grassroots elections, exert prominent effects on police trust. The significant correlation between grassroots elections and police trust can be regarded as an effect of grassroots election participation on the public. The public achieve higher discursive power on grassroots community affairs through participating in grassroots election. Both the urban community committees and village committees are grassroots autonomy organizations, but the latter is far more important than the former. Especially since the mid-1980s, elections at village level were massive and fierce and were far more competitive than community committee election in urban areas. Then, the next question is, why does the urban grassroots election accelerates police trust more than the rural area one does in our findings? Participation in urban and rural grassroots elections could be considered as a form of pro-establishment action, but the competitiveness of village election makes it more tolerant on villagers with anti-establishment tendencies. Thus, grassroots elections amplifies less on villagers' police trust than that on urban residents' police trust.

Distinctive from the effects of grassroots elections on police trust, rightful resistance tends to produce complaints against the police. Normally, rightful resistance only takes place when protesters are driven into desperation. These people may hold a negative attitude towards government agencies because they have been treated unfairly. Besides, 
although protests take place in a variety of forms, most of the struggles are institutionalized and peaceful. The tension between the public and the government or the police is often elevated in the struggles, sometimes even reaches a degree of violence, resulting in negative assessment of the regime.

It is worth noticing that the data shows participation in community affairs failed to enhance the respondents' police trust. Although more participation in community affairs could have more contact with the police, it is not a substitute way to improve police trust. It remains to be further explored on the internal mechanism of the influence of community involvement on police trust.

Thirdly, we find that some key indicators of the respondents' social status have an important impact on police trust. Our analysis proves correlations between police trust and gender, ethnicity (minority or majority), education level, and Hukou. That is to say, male respondents have lower police trust than females; Han nationality's police trust is lower than ethnic minority's; young people trust police less than the elder; police trust of higher educated individuals is lower than that of lower educated; and urban residents trust police less than rural residents. Social vulnerable groups are usually those who perform dissatisfaction and distrust to the system, while as mentioned above, males, Han nationality, youth, highly educated people, and urban residents do not belong to social vulnerable groups in a traditional sense. Social reform and sustained economic growth may impelled the expectations of these groups towards the government continuously, as well as their discontent with the government, meanwhile their trust to government presents a declining tendency. Such phenomenon was quite similar to "critical citizens" observed in Western democracy countries since the 1990s (Norris 1999). The relationship between these groups and police trust needs to be discussed in the next stage.

Last but not the least, we find that public trust towards police is closely tied to their trust in society and justice. Police trust can be regarded as a component of interconnected social attitudes in a wider range. Positive evaluation of one aspect of the system will affect the evaluation of another. In our research, respondents with relatively higher universal trust and special trust also display higher police trust. The higher recognition of social justice respondents have, the greater police trust they show. Future studies on police trust should continue to consider these attitudinal factors.

\section{Conclusions}

It is worthwhile to note that due to the utilizing of second-hand survey data, our research have some drawbacks as below. Firstly, our research lacks several predictive variables which have been proved effective in past studies. For example, recent survey shows that expressive concerns (such as cohesiveness of neighborhood and life quality) and instrumental attention (such as concerns on becoming victim of crime) are validated predictive variables in Chinese people's police trust (such as Sun et al. 2013a, b). Similarly, the experience of individual contact with the police also plays a role in the assessment of police (Schur et al 2003; Weitzer \& Tuch 2002). In order to better comprehend Chinese people's police trust, further research should take into account of these independent variables as predictive variables. 
Another limitation in this study is the use of single item to measure police trust. Although this was not rare in previous literature and is supported by recent findings that Chinese people's police trust is a single dimension (Sun et al. 2013a, b), measuring in a single dimension risks simplifying social phenomenon and misunderstanding (Hudson \& Kuhner 2010). Future researches should take a multi-dimensional view, such as trust on the basis of procedures and on the basis of results (Tyler \& Huo 2002), employing integrated and comprehensive index to measure police trust in China.

Thirdly, because this research is a cross-sectional study, which the respondents were surveyed at a single point of time, we could not solve the endogenous problem of variables. In other words, although regression model demonstrates statistically significant influence on police trust in grassroots election and rightful resistance, we could not discreetly conclude that the former was the cause and the latter was the result. We could only confirm the statistic correlation between the former and the latter. In order to solve this problem, it remains to be studied vertically through longitudinal data collection.

Our research could inspire policy-makings in two ways. On the one hand, police trust with no doubt is an essential part of political trust and, at the same time, a key indicator of people's trust on political system. We find pro-establishment activities such as higher external efficacy, participation in grassroots election, and comparatively higher social trust and justice could enhance police trust. The government should accelerate the pace of systematic political reform, so that people will have more political participation channels.

On the other hand, our research indicates anti-establishment activities, such as rightful resistance, will lead to the loss of police trust. Therefore, China's current petition system may need corresponding reform, in order to set up more effective expression channels and civil rights protection mechanism. If public discontent does not dredge in time, it may uplift to radical activities that could extensively challenge the existing system. Thus, while political reform could not necessarily ensure the promotion of political trust, it can greatly enhance the legitimacy of government.

Competing interests

The author declare that they have no competing interests.

Authors' contributions

The author have read and approved the final manuscript.

Received: 27 August 2015 Accepted: 22 December 2015

Published online: 13 January 2016

References

Aberbach, Joel D., and Jack L. Walker. 1970. Political trust and racial ideology. American Political Science Review 64: 1199-1220.

Balch, G. 1974. Multiple indicators in survey research: the concept 'sense of political efficacy'. Political Methodology 1(2): 1-43.

Bernstein, T., and X. Lu. 2003. Taxation without representation in contemporary rural China. Cambridge: Cambridge University Press.

Bialer, Seweryn. 1980. Stalin's successors: leadership, stability, and change in the Soviet Union. New York: Cambridge University Press.

Brehm, J., and W. Rahn. 1997. Individual-level evidence for the causes and consequences of social capital. American Journal of Political Science 41: 999-1023.

Campbell, A., G. Gurin, and W.E. Miller. 1954. The voter decides. Evanston: Row, Peterson and Company.

Cao, L., and C. Hou. 2001. A comparison of confidence in the police in China and the United States. Journal of Criminal Justice 29: 87-99.

Catterberg, G., and A.Moreno. 2006. "The Individual Bases of Political Trust: Trends in New and Established Democracies." International Journal of Public Opinion Research 18(1):31-48.

Cole, R. 1973. Toward a model of political trust: a causal analysis. American Journal of Political Science 17(4): 809-17.

Chen, J., C. Lu, and Y. Yang. 2007. "Popular Support for Grassroots Self-Government in Urban China: Findings from a Beijing Survey." Contemporary China 33(4):505-28. 
Easton, David, and Dennis J. 1967. "The child's acquisition of regime norms: political efficacy". The American Political Science Review 61: 25-38.

Finkel, Steven E. 1985. Reciprocal effects of participation and political efficacy: a panel analysis. American Journal of Political Science 29(4): 891-913.

Finkel, Steven E. 1987. The effects of participation on political efficacy and political support: evidence from a West German panel. The Journal of Politics 49(2): 441-464.

Friedrich, C., M. Curtis, and B. Barber. 1969. Totalitarianism in perspective: three views. New York: Praeger.

Hahn, C. 1998. Becoming political: comparative perspectives on citizenship education. Albany: State University of New York Press.

Hess, R.D., and J.V. Torney. 1967. The development of political attitudes in children. New York: Doubleday \& Company.

Hetherington, Marc J. 1998. The political relevance of political trust. American Political Science Review 92(4): 791-808.

Hofstede, G. 2001. Culture's Consequences: Comparing Values, Behaviors, Institutions, and Organizations Across Nations. Thousand Oaks, CA: Sage.

Hu, R. 2001. Rational choice and implementation of policies: a case study of resident committee election in rural China. Shanghai: Shanghai Yuandong Chubanshe.

$\mathrm{Hu}$, Rong. 2005. Economic development and the implementation of village elections in rural China. Journal of Contemporary China 14(44): 427-444.

Hudson, J., and S. Kuhner. 2010. "Beyond the Dependent Variable Problem: TheMethodological Challenges of Capturing the Productive and ProtectiveDimensions of Social Policy." Social Policy and Society 9(2): 167-79.

Huo, J. 2005. Political efficacy in authoritarian and democratic Taiwan: how political institutions affect political efficacy. Chicago: Paper presented at annual meeting of the Midwest Political Science Association.

Inkles, Alex, and Raymond A. Bauer. 1959. The soviet citizen: daily life in a totalitarian society. Cambridge: Harvard University Press.

Jennings, M. Kent. 1997. Political participation in the Chinese countryside. The American political science review 91(2): 361-372.

Kahne, J., and J. Westheimer. 2002. "The limits of efficacy: educating citizens for a democratic society.". Boston: Paper presented at the annual meeting of American Political Science Association.

Kenski, Kate, and N.J. Stroud. 2006. Connections between Internet use and political efficacy, knowledge, and participation. Journal of broadcasting \& electronic media 50(2): 173-192.

Lai, Y., L. Cao, and J. Zhao. 2010. The impact of political entity on confidence in legal authorities: a comparison between China and Taiwan. Journal of Criminal Justice 38: 934-41.

Michelson, M.R. 2000. Political efficacy and electoral participation of Chicago Latinos. Social science quarterly 81 (1): 136-150.

Morrell, M.E. 2003. Survey and experimental evidence for a reliable and valid measure of internal political efficacy. Public Opinion Quarterly 67: 589-602.

Newton, K., and S. Zmerli. 2011. Three forms of trust and their association. European Political Science Review 3(2): 169-200.

Niemi, R.G., S.C. Craig, and F. Mattei. 1991. Measuring internal political efficacy in the 1988 national election study. American Political Science Review 85(4): 1407-1413.

Norris, P. 1999. Critical Citizens: Global Support for Democratic Government. Oxford: Oxford University Press.

Nie, Norman, and Sydney Verba. 1975. "Political participation". In Handbook of Political Science. Reading, Mass: AddisionWesley Educational Publishers Inc.

O'Brien, Kevin. 1996. "Rightful resistance". World Politics 49(1): 31-55.

O'Brien, Kevin, and Lianjiang Li. 2006. Rightful Resistance In Rural China. New York and Cambridge: Cambridge University Press.

Pasek, J., L. Feldman, D. Romer, and H. Jamieson. 2008. Schools as incubators of democratic participation: building long-term political efficacy with civic education. Applied Developmental Science 12(1): 26-37.

Putnam, Robert. 1993. Making Democracy Work: Civic Traditions in Modern Italy. Princeton: Princeton University Press.

Putnam, R. 2000. Bowling alone: the collapse and revival of American community. New York: Simon and Schuster.

Rotter, J. 1967. "ANew Scale for theMeasurement of Interpersonal Trust." Journal of Personality 35(4):651-65.

Schur, L., T. Shields, and K. Schriner. 2003. Can I make a difference? Efficacy, employment, and disability. Political Psychology 24(1): 119-149.

Schyns, P., and C. Koop. 2013. Political distrust and social capital in Europe and the USA. Social Indicators Research 96(1): 145-167.

Sullivan, J.L., and E. Riedel. 2001. "Efficacy: Political." In International Encyclopedia of Social and Behavioral Sciences. New York: Elsevier Science Ltd.

Sun, I., R. Hu, and Y. Wu. 2012. "Social capital, political participation, and public trust in police in urban China.". Australia and New Zealand Journal of Criminology 45(1): 87-105.

Sun, I., R. Hu, D. Wong, X. He, and J. Li. 2013a. "One country, three populations: trust in police among migrants, villagers, and urbanites in China". Social Science Research 42(6): 1737-1749.

Sun, I., R. Hu, D. Wong, X. He, and J. Li. 2013b. "One country, three populations: trust in police among migrants, villagers, and urbanites in China". Social Science Research 42(6): 1737-1749.

Tanner, M. 2004. China rethinks unrest. The Washington Quarterly 27(3): 137-156.

Tyler, T., and Y. Huo. 2002. Trust in the Law: Encouraging Public Cooperation with the Police and Courts. New York: Russell Sage Foundation.

Uslaner, E. 2002. The moral foundations of trust. Cambridge: Cambridge University Press.

Wang, Y., N. Rees, and B. Andreosso-O'Callaghan. 2004. Economic change and political development in China: findings from a public opinion survey. Journal of Contemporary China 13(39): 203-222.

Weitzer, R., and S. Tuch. 2002. "Perceptions of Racial Profiling: Race, Class, and Personal Experience."Criminology 40(2):435-46.

Wright, James D. 1975. Does acquiescence bias the "index of political efficacy?". The Public Opinion Quarterly 39(2): 219-226.

Wu, Yuning, and Sun Ivan. 2009. Citizen trust in police: the case of China. Police Quarterly 12: 170-191.

Wu, Y., and I. Sun. 2010. "Perceptions of Police: An Empirical Study of Chinese College Students." Policing: An International Journal of Police Strategies and Management 33(1):93-113. 